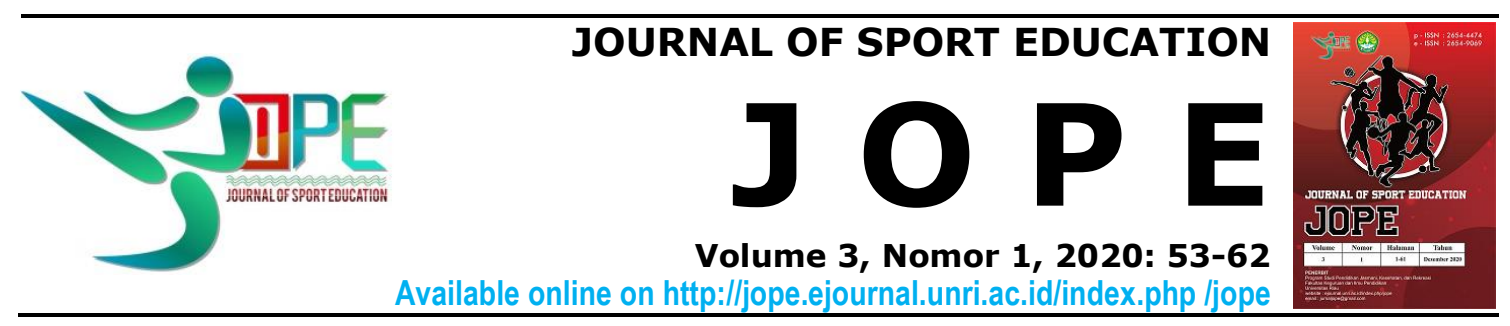

\title{
Upaya meningkatkan servis atas bolavoli mini menggunakan metode pembelajaran game terhadap siswa sekolah dasar
}

\author{
Sukari ${ }^{1}$, Tito Pangesti Adji ${ }^{2}$, Kukuh Hardopo Putro ${ }^{3}$. \\ ${ }^{1}$ Sekolah Dasar Negeri 02 Sumberingin Kidul, ${ }^{2,3}$ Universitas Negeri Yogyakarta \\ Sukari110865@gmail.com¹ ${ }^{1}$ titopangesti.2019@student.uny.ac.id ${ }^{2}$, \\ kukuhhardopo.2018@student.uny.ac.id ${ }^{3}$
}

Received 25 September 2020; Revised 08 November 2020; Accepted 10 November 2020

doi) http://dx.doi.org/10.31258/jope.2.2.53-62

\begin{abstract}
Abstrak
Penelitian ini bertujuan untuk meningkatkan kemampuan servis atas bolavoli mini pada siswa sekolah dasar. Jenis penelitian adalah action research yang bertujuan untuk memecahkan masalah yang terjadi dalam suatu proses pembelajaran. Sampel dalam penelitian ini berjumlah 20 orang siswa. Teknik analisis data menggunakan teknik analisis data deskriptif persentase. Berdasarkan hasil kumulatif siklus 1 siswa diketahui belum tuntas sebanyak 55\%. Kesimpulan masih banyak kekurangan dan jauh dari apa yang diharapkan yakni $70 \%$ ketuntasan dari seluruh siswa. Dari hasil kumulatif siklus 2 diketahui $75 \%$ siswa tuntas, $25 \%$ belum tuntas. Hasil akhir yang sudah diperoleh dari dua siklus yang sudah dilakukan dengan menggunakan metode pembelajaran game untuk meningkatkan kemampuan siswa dalam melakukan servis atas bolavoli mini sudah sesuai dan melampaui harapan guru sebanyak $70 \%$ ketuntasan.
\end{abstract}

Kata Kunci: hasil belajar, bolavoli, servis atas, game

\section{Efforts to improve service for mini volleyball using game learning methods for elementary school students}

\begin{abstract}
This study aims to improve the ability to serve mini volleyball in elementary school students. This type of research is action research that aims to solve problems that occur in a learning process. The sample in this study amounted to 20 students. The data analysis technique used the percentage descriptive data analysis technique. Based on the cumulative results of cycle 1 , it is known that $55 \%$ of students have not completed it. The conclusion is that there are still many shortcomings and it is far from what was expected, namely $70 \%$ of the completeness of all students. From the cumulative results of cycle 2, it is known that $75 \%$ of students have completed, 25\% have not. The final results that have been obtained from the two cycles that have been carried out using the game learning method to improve the students' ability to serve mini volleyball are appropriate and exceed the teacher's expectations as much as 70\% completeness.
\end{abstract}

Keywords: learning outcomes, volleyball, top service, games

How To Cite: Sukari, Adji, T. P., Putro, K. H. (2020). Upaya meningkatkan servis atas bolavoli mini menggunakan metode pembelajaran game terhadap siswa sekolah dasar. Journal of Sport Education (JOPE), 3 (1), 53-62. 


\section{PENDAHULUAN}

Permainan bolavoli mini memegang peranan penting dalam mengembangkan dan kemampuan dan teknik bermain bolavoli mini pada siswa. Dalam kesempatan ini justru akan mempermudah atlet muda untuk mempelajari keterampilan dalam bermain bolavoli, sebab untuk usia anak yang tergolong masih dalam tahap anak-anak yang memang dalam fase untuk belajar meski pasti sedikit mengalami kendalan serta kesulitan dalam prosesnya untuk mengembangkan keterampilan bermain bolavoli, namun dalam fase ini justru mereka akan lebih cepat serta lebih mudah nantinya untuk mempelajari setiap gerakan yang benar dalam bermain bolavoli, berbeda hal ketika mereka memasuki pada usia dewasa justru perkembangannya tidak secepat pada masa sebelumnya karena tingkat kesulitan pada usia dewasa lebih komplek baik dari segi fisik maupun pembelajarannya. Dalam permainan bolavoli mini menyimpan banyak sekali manfaat serta banyak mengandung kesempatan-kesempatan terhadap para siswa untuk lebih menumbuh kembangkan berbagai aspek dalam diri para siswa baik itu kemampuan secara fisik, mental dan sosial sebagai dasar dalam pengembangan prestasi bolavoli sebenarnya (Mahedero et al., 2015). Ada banyak teknik yang ada dalam permainan bolavoli dari mulai teknik servis, teknik pasing, teknik smash, dan juga teknik blok yang benar yang harus diketahui oleh setiap pemain bolavoli (Palao et al., 2009). Dalam hal ini guru lebih untuk memfokuskan terhadap para siswa mengenai bagaimana upaya yang harus dilakukan untuk meningkatkan kemampuan para siswa dalam melakukan servis atas terutama bagi siswa pemula, karena untuk perihal siswa pemula yang baru belajar bolavoli lebih membutuhkan pembelajaran yang tepat agar lebih mudah dalam proses pembelajaran untuk kedepannya bagi siswa. Pembahasan fokus pada siswa sekolah dasar otomatis guru olahraga selaku pengajar dalam bidang olahraga yang menjadi pengajar sekaligus pelatih dalam pembelajaran untuk meningkatkan kemampuan servis atas pada para peserta didiknya. Selain itu, guru olahraga juga harus mengerti peraturanperaturan, teknik, dan taktik permainan bolavoli (Kim, 2016). Seorang guru olahraga juga diwajibkan mempunyai wawasan yang luas terhadap dunia olahraga serta selalu kreativitas dan berinovasi untuk menyusun serta merancang suatu progam pembelajaran terhadap suatu teknik gerakan yang diawali dari gerakan yang sederhana kearah gerakan yang lebih kompleks atau sulit dengan sesuai dengan tahapannya, agar apa yang menjadi tujuan dalam pembelajaran yang diajarkan dapat tercapai sesuai dengan apa yang sudah direncanakan (John, 2006). Oleh sebab itu, bagi seorang guru olahraga wajib untuk selalu mengetahui serta selalu memahami beraneka macam bentuk permainan dan pelatihan yang lebih ringan serta lebih sederhana dan juga nantinya mampu dalam menerapkan metode pembelajaran yang sesuai dan cocok terhadap para siswa, sehingga para siswa mudah memahami materi tak terkecuali bagi siswa sekalipun itu 
Journal of Sport Education (JOPE), 3 (1) 2020 - 55

Sukari ${ }^{1}$, Tito Pangesti Adji ${ }^{2}$, Kukuh Hardopo Putro ${ }^{3}$.

yang baru mengetahui mengenai apa itu permainan bolavoli (Stolz \& Pill, 2014). Pembelajaran materi olahraga atau sering dikenal dengan pendidikan jasmani yang diajarkan disekolah dasar, dalam hal ini lebih berfokus pada cabang olahraga bolavoli, masih banyak mengalami kendala dalam proses pembelajaran baik dalam aspek aturan secara resmi maupun pembelajaran menyangkut kondisi fisik untuk cabang olahraga itu sendiri yang sesungguhnya dalam hal ini adalah bolavoli khususnya dalam bolavoli mini, dikarenanakan untuk tingkat perkembangan serta kekuatan fisik siswa belum begitu kuat dan stabil seperti para pemain yang dikategorikan usia dewasa. Dari hal tersebut dapat dinilai bahwasannya hampir untuk keseluruhan cabang olahraga yang ada sekarang untuk pemberian pembelajaran serta pelatihan kondisi fisik harus disesuaikan dengan kondisi para siswa untuk mempermudah guru dalam pelaksanaan prosesnya nanti serta dengan program pembelajaran dan pelatihan yang diawali dengan gerakan dari yang sederhana kearah gerakan yang lebih kompleks. Permasalahan yang sudah dapat teridentifikasi disini yang dihadapi guru olahraga secara langsung dilapangan adalah menyangkut kemampuan para siswa kelas VI SDN 02 Sumberingin Kidul dalam proses melaksanakan servis atas bolavoli mini yang belum begitu maksimal dan belum seperti yang diharapkan oleh guru. Hal ini ditunjukkan dari data yang menunjukkan bahwa masih $40 \%$ siswa yang mampu melakukan servis atas dengan tuntas, sedangkan $60 \%$ lainnya siswa belum bisa menuntaskan pada pokok bahasan ini. Masih rendahnya kemampuan servis atas tersebut yang masih dibawah 50\% dari jumlah keseluruhan siswa dalam satu kelas membuat guru mencari tahu serta menelusuri faktor apa yang menjadi penyebab hal tersebut bisa terjadi, serta mengevaluasi mengenai gerakan teknik servis atas para siswa, mengidentifikasi kondisi fisik para siswa, ataupun mengoreksi metode pembelajaran yang diajarkan apakah sudah sesuai dengan kondisi para siswa. Pada fase seperti ini kunci utama keberhasilan terletak bagaimana seorang guru olaharaga dapat memberikan gagasannya serta menuangkan ide-idenya untuk dapat meningkatkan kemampuan servis atas bolavoli mini para siswa didiknya. Mayoritas yang terjadi di lapangan adalah para siswa masih kesulitan dalam melakukan teknik servis atas dengan benar dengan berbagai faktor kendala yang ada disana. Dari permasalahan yang sudah diketahui tersebut bahwasannya para siswa kelas VI SDN 02 Sumberingin Kidul dalam melaksanakan gerakan servis atas dengan teknik yang benar masih terlampau banyak kekurangan serta belum bisa maksimal dalam melakukannya, dalam hal ini peneliti akhirnya mengambil keputusan dengan menggunakan metode pembelajaran game dalam pembelajaran terhadap para siswa kelas VI SDN 02 Sumberingin Kidul untuk meningkatkan kemampuan servis atas mereka. 
Journal of Sport Education (JOPE), 3 (1) 2020 - 56

Sukari ${ }^{1}$, Tito Pangesti Adji $i^{2}$, Kukuh Hardopo Putro ${ }^{3}$.

\section{METODE}

Jenis penelitian adalah action research atau penelitian tindakan yang dimana penelitian ini bertujuan untuk memecahkan masalah yang terjadi dalam suatu proses pembelajaran. Untuk penelitian kali ini peneliti menggunakan penelitian tindakan kelas (PTK). PTK sendiri mempunyai pengertian suatu metode penelitian yang mempunyai sifat reflektif yang memiliki tujuan untuk meningkatkan hasil dari pembelajaran yang kurang maksimal (Supardi \& Suharsimi, 2009). Penelitian ini bersifat deskriptif yang memiliki definisi penelitian yang menggambarkan suatu masalah serta bagaimana penyelesaiannya serta hasilnya dengan penjelasan secara deskripsi. Tahapan penelitian tindakan pada suatu siklus meliputi perencanaan atau pelaksanaan observasi dan refleksi. Siklus ini berlanjut dan akan dihentikan jika sesuai dengan kebutuhan dan dirasa sudah cukup. Yang menjadi penelitian adalah suluruh siswa kelas VI SDN 02 Sumberingin Kidul dengan jumlah siswa 20 orang siswa. Pada fase refleksi siklus pertama, guru menganalisis proses tindakan pada siklus pertama dan memperbaiki hal-hal yang tepat untuk diatur ulang pada fase perencanaan di siklus kedua. Penelitian ini menggunakan data kuantitatif dan kualitatif. Data digunakan sebagai refleksi sebagai bahan evaluasi untuk merancang program siklus selanjutnya. Untuk penilaiannya sendiri ada tiga bentuk penilaian yakni afektif, kognitif dan psikomotor. Penelitian ini menggunakan instrumen RPP, Lembar Pengamatan Individu, Lembar Pengamatan Klasikal dan terakhir Kuesioner. Teknik analisis data yang digunakan untuk data kuantitatif berupa hasil belajar kognitif, dianalisis dengan menggunakan teknik analisis deskriptif persentase dengan menentukan persentase ketuntasan belajar dan mean (rata-rata) kelas. Rumus sebagai berikut: $\mathrm{P}=($ Jumlah siswa tuntas belajar/ jumlah siswa) x 100\%

Tabel 1. Kriteria Ketuntasan

\begin{tabular}{cc}
\hline Syarat Ketuntasan & Kualifikasi \\
\hline$\geq 70$ & Tuntas \\
\hline$\leq 70$ & Tidak Tuntas
\end{tabular}

Sumber: (Supardi \& Suharsimi, 2009)

Hasil akhir secara kuantitatif baik nilai kognitif, afektif dan psikomotor adalah sebagai berikut : Nilai Kognitif/ afektif/ psikomotor $=($ skor perolehan $/$ skor maksimal) x 100. Siswa aktif mendapat skor 1 sesuai dalam instrumen, skor 0 untuk tidak sesuai instrumen dan skor maksimal 12. Selanjutnya untuk rumus nilai akhir adalah sebagai berikut: Total Kognitif x $\mathbf{3 0 \%}+$
Total Afektif x 20\% + Total Psikomotor x 50\% $=$ Total Akhir. Pemberian nilai kognitif $30 \%$, afektif $20 \%$ dan psikomotor $50 \%$ dikarenakan dalam pembelajaran pendidikan jasmani dominan untuk kegiatan olah fisik.

Pendeskripsian kalimat yang dipisahkan menurut kategori untuk memperoleh kesimpulan hasil belajar dan observasi disini 
Journal of Sport Education (JOPE), 3 (1) 2020 - 57

Sukari ${ }^{1}$, Tito Pangesti Adji $i^{2}$, Kukuh Hardopo Putro ${ }^{3}$.

masuk dalam data kualitatif. Keberhasilan berikut:

belajar siswa diukur dengan kriteria sebagai

Tabel 2. Kriteria Keberhasilan Belajar

\begin{tabular}{cc}
\hline Tingkat Berhasil \% & Arti \\
\hline$\geq 80 \%$ & Sangat tinggi \\
\hline $60-79 \%$ & Tinggi \\
\hline $40-59 \%$ & Sedang \\
\hline $20-39 \%$ & Rendah \\
\hline$<20 \%$ & Sangat Rendah \\
\hline
\end{tabular}

Sumber: (Supardi \& Suharsimi, 2009)

Tabel 3. Kriteria Keberhasilan Belajar

\begin{tabular}{lll}
\hline Pencapaian tujuan pembelajaran & \multicolumn{1}{c}{ Kualifikasi } & Tindakan keberhasil-an pembelajar-an \\
\hline $85-100 \%$ & Sangat baik (A) & Berhasil \\
\hline $75-84 \%$ & Baik (B) & Berhasil \\
\hline $60-74 \%$ & Cukup (C) & Berhasil \\
\hline $40-59 \%$ & Kurang (D) & Tidak Berhasil \\
\hline$<40 \%$ & Jelek (E) & Tidak Berhasil \\
\hline
\end{tabular}

Sumber: (Arikunto, 2013)

\section{HASIL DAN PEMBAHASAN}

Hasil

\section{Hasil Nilai Akhir Siklus 1}

\section{Pretest Servis Atas Bolavoli Mini}

Berdasarkan data pada tabel 4 didapatkan hasil $40 \%$ siswa atau 8 siswa yang bisa lulus sesuai dengan KKM yang sudah ditetapkan, sedangkan $60 \%$ siswa sisanya yaitu 12 siswa masih belum bisa lulus.

\section{Tes Penilaian Psikomotor}

Berdasarkan data pada tabel 4 tingkat ketuntasan belajar mencapai 11 siswa atau $55 \%$ dari keseluruhan siswa sedangkan yang belum tuntas mencapai 9 siswa atau $45 \%$. Pada pembelajaran siklus I, siswa belum sepenuhnya memahami apa yang dimaksudkan model pembelajaran game. Sebagian besar siswa masih bercanda dan belum serius saat melakukan servis atas. Hal ini dapat diperjelas pada hasil non tes siklus I.

\section{Tes Penilaian Kognitif}

Tingkat partisipasi siswa terhadap pembelajaran bolavoli mini ditunjukkan melalui hasil lembar soal siswa. Tingkat pemahaman siswa pada siklus I disajikan pada tabel berikut. Berdasarkan tabel 4 diketahui bahwa siswa masih belum memiliki ketertarikan terhadap permainan bolavoli. Hal ini dapat dilihat dari 10 siswa yang lulus atau persentase sebesar 50\% dari keseluruhan siswa. Artinya siswa masih belum memiliki motivasi yang tinggi dalam melakukan servis atas dengan baik. Bedasarkan kekurangan pada siklus I dilakukan perencanaan ulang guna melaksanakan perbaikan di tindakan siklus II.

\section{Tes Penilaian Afektif}

Berdasarkan data pada tabel 4 diperoleh hasil penilaian afektif, diperoleh tingkat partisipasi siswa sebesar $88,25 \%$.

\section{Hasil Akhir Penilaian Siklus 1}

Dari data tabel 4 diketahui 55\% belum tuntas dan yang tuntas mencapai 45\%. Dari hal menjadikan target $70 \%$ ketuntasan dari 
jumlah siswa belum tercapai. Berkaca dari hasil gambar 4, hasil akhir masih dibawah $50 \%$ ketuntasan dari jumlah kesulurahan siswa. Peneliti menemukan beberapa permasalahan yang terjadi antara lain sebagai berikut. Perhatian siswa masih kurang, Siswa sering bercanda untuk melakukan teknik servis atas, Peralatan minim, melihat banyaknya bola yang tidak sama dengan banyaknya pasangan siswa dalam melakukan teknik servis atas. Oleh karena itu peneliti memutuskan untuk melanjutkan ke tahap penelitian siklus 2 untuk meningkatkan kemampuan siswa agar targer yang diharapkan oleh peneliti yang lebih dari $70 \%$ bisa tercapai.

\section{Hasil Nilai Akhir Siklus 2}

\section{Tes Penilaian Psikomotor}

Dari data pada tabel 5, diketahui banyaknya siswa yang tuntas pada percobaan praktek servis atas dengan jarak 6 meter sebanyak 17 siswa atau $85 \%$ sedangkan yang tidak tuntas sebanyak 3 siswa atau $15 \%$.

\section{Tes Penilaian Kognitif}

Dari data pada tabel 5, diketahui bahwa persentase sebesar $75 \%$ dari keseluruhan siswa lulus dalam menjawab soal yang diberikan oleh guru dalam bentuk lembar soal.

\section{Tes Penilaian Afektif}

Dari data pada tabel 5, diperoleh tingkat partisipasi siswa sebesar $89,5 \%$.

\section{Hasil Akhir Tes Siklus 2}

Dari data pada tabel 5, diketahui $75 \%$ dari jumlah siswa telah mencapai ketuntasan dan rata-rata dalam kelas penelitian 77,75 . Ini menunjukan bahwa target yang di inginkan peneliti yaitu lebih dari $70 \%$ dari jumlah siswa telah tercapai. Pada siklus II servis atas dilakukan dengan model pembelajaran game yaitu berjarak 6 meter. Antusiasme siswa terhadap materi yang disampaikan tinggi. Selain itu dengan, menggunakan model pembelajaran game, siswa dituntut untuk terbiasa melakukan servis atas. Kendala yang dialami pada siklus 1 diminimalisir dan dicari solusi dari permasalahan tersebut. Sehingga pada pembelajaran di siklus II berjalan dengan lancar dan kendala-kendala di pembelajaran siklus I sudah bisa ditanggulangi pada pembelajaran siklus II dengan solusi yang tepat.

Tabel 4. Lembar Penilaian Akhir Siswa Siklus 1

\begin{tabular}{llccccccc}
\hline \multirow{2}{*}{ No } & \multirow{2}{*}{ Nama } & \multicolumn{5}{c}{ Nilai } & \multirow{2}{*}{ Total Nilai } & \multicolumn{2}{c}{ Ket. } \\
\cline { 3 - 5 } \cline { 5 - 6 } & & Afektif & Kognitif & Psikomotor & & TL \\
\hline 1 & Adam & 100 & 80 & 90 & 90 & L & \\
\hline 2 & Ainur & 75 & 80 & 40 & 65 & & TL \\
\hline 3 & Aryudan & 85 & 55 & 40 & 60 & & TL \\
\hline 4 & Berlian & 85 & 40 & 20 & 48 & & TL \\
\hline 5 & Bima & 70 & 80 & 30 & 60 & & TL \\
\hline 6 & Deni & 100 & 60 & 60 & 73 & L & \\
\hline 7 & Elisa & 75 & 40 & 20 & 45 & & TL \\
\hline 8 & Fendi & 100 & 80 & 70 & 83 & L & \\
\hline 9 & Hanid & 90 & 75 & 60 & 75 & L & \\
\hline 10 & Julia & 100 & 75 & 70 & 82 & L & \\
\hline 11 & Mei & 90 & 40 & 40 & 57 & & TL \\
\hline
\end{tabular}


Journal of Sport Education (JOPE), 3 (1) 2020 - 59

Sukari $^{1}$, Tito Pangesti Adji $i^{2}$, Kukuh Hardopo Putro ${ }^{3}$.

Lanjutan Tabel 4. Lembar Penilaian Akhir Siswa Siklus 1

\begin{tabular}{lccccccc}
\hline \multirow{2}{*}{ No } & \multirow{2}{*}{ Nama } & \multicolumn{3}{c}{ Nilai } & \multirow{2}{*}{ Total Nilai } & \multicolumn{2}{c}{ Ket. } \\
\cline { 3 - 5 } & & Afektif & Kognitif & Psikomotor & & TL \\
\hline 12 & Miftakhul & 85 & 80 & 80 & 82 & L & \\
\hline 13 & Musama & 100 & 50 & 80 & 77 & L & \\
\hline 14 & Najwa & 100 & 75 & 60 & 78 & L & \\
\hline 15 & Putri & 80 & 45 & 20 & 48 & & TL \\
\hline 16 & Revalentina & 70 & 40 & 10 & 40 & & TL \\
\hline 17 & Rio & 100 & 80 & 100 & 93 & L & \\
\hline 18 & Sahrukan & 85 & 30 & 70 & 62 & & TL \\
\hline 19 & Untay & 90 & 45 & 50 & 62 & & TL \\
\hline 20 & Wiwik & 85 & 45 & 30 & 53 & & TL \\
\hline & Jumlah & 1765 & 1195 & 1040 & 1294 & 9 & 11 \\
\hline & Persentase & $88,25 \%$ & $59,75 \%$ & $52 \%$ & $64,7 \%$ & $45 \%$ & $55 \%$ \\
\hline
\end{tabular}

Tabel 5. Lembar Hasil Nilai Akhir Siklus II

\begin{tabular}{ccccccccr}
\hline \multirow{2}{*}{ No } & \multirow{2}{*}{ Nama } & \multicolumn{3}{c}{ Nilai } & \multirow{2}{*}{ Total Nilai } & \multicolumn{2}{c}{ Ket. } \\
\cline { 3 - 4 } & & Afektif & Kognitif & Psikomotor & & L & TL \\
\hline 1 & Adam & 100 & 90 & 100 & 97 & L & \\
\hline 2 & Ainur & 75 & 80 & 70 & 75 & L & \\
\hline 3 & Aryudan & 85 & 80 & 70 & 78 & L & \\
\hline 4 & Berlian & 85 & 75 & 40 & 67 & & TL \\
\hline 5 & Bima & 70 & 50 & 70 & 63 & & TL \\
\hline 6 & Deni & 100 & 80 & 80 & 87 & L & \\
\hline 7 & Elisa & 75 & 40 & 30 & 48 & & TL \\
\hline 8 & Fendi & 100 & 80 & 90 & 90 & L & \\
\hline 9 & Hanid & 90 & 75 & 80 & 81 & L & \\
\hline 10 & Julia & 100 & 80 & 80 & 86 & L & \\
\hline 11 & Mei & 90 & 70 & 50 & 70 & L & \\
\hline 12 & Miftakhul & 85 & 80 & 80 & 82 & L & \\
\hline 13 & Musama & 100 & 70 & 90 & 87 & L & \\
\hline 14 & Najwa & 100 & 55 & 70 & 75 & L & \\
\hline 15 & Putri & 80 & 50 & 70 & 67 & & TL \\
\hline 16 & Revalentina & 80 & 50 & 30 & 53 & & TL \\
\hline 17 & Rio & 100 & 90 & 100 & 97 & L & \\
\hline 18 & Sahrukan & 100 & 80 & 80 & 87 & L & \\
\hline 19 & Untay & 90 & 75 & 80 & 82 & L & \\
\hline 20 & Wiwik & 85 & 85 & 80 & 83 & L & \\
\hline & Jumlah & 1790 & 1435 & 1440 & 1555 & 15 & 5 \\
\hline & Rata-rata & 89,5 & 71,75 & 72 & 77,75 & 0 & 0 \\
\hline & Persentase & $89,5 \%$ & $71,75 \%$ & $72 \%$ & $77,75 \%$ & $75 \%$ & $25 \%$ \\
\hline
\end{tabular}

\section{Pembahasan}

Temuan dalam penelitian ini adalah terjadinya peningkatan pembelajaran service atas bola voli mini menggunakan metode game dalam pembelajaran olahraga pada tingkat sekolah dasar. Hal ini berarti bahwa metode game yang digunakan dalam pembelajaran service atas bola voli mini efektif untuk meningkatkan prestasi belajar bola voli mini pada materi service atas. Peningkatan ini dapat dilihat dari selisih persentase nilai siklus I dan II pada hasil penelitian yang sudah dijabarkan pada bab hasil. Terjadi peningkatan sebanyak 30 persen. Hal ini sejalan dengan penelitian (Astuti, 2017) yang menghasilkan temuan 
bahwa metode bermain dapat meningkatkan keterampilan bola voli. Penelitian serupa juga pernah dilakukan oleh (Kamil et al., 2018) yang menyatakan terdapat pengaruh yang signifikan yaitu meningkatnya kemampuan passing SSB Bina Remaja Lumindai Kota Sawahlunto dengan menggunakan metode bermain. Diperkuat oleh (Atsani, 2020) dalam penelitiannya yang berjudul "meningkatkan kemampuan passing bawah bola voli dengan metode bermain' dapat disimpulkan bahwa metode bermain dapat meningkatkan kemampuan passing bawah siswa. Metode bermian dapat meningkatkan Keterampilan tersebut tentu salah satunya adalah kemampuan service atas bola voli mini. Selanjutnya pada penelitian lain, yang hanya terletak pada metodenya saja. Metode game tersebut dibandingkan dengan metode drill. Sebelumnya metode drill pernah digunakan (Fanani, 2020) dalam penelitiannya untuk meningkatkan teknik dasar passing bola voli, dalam penelitian itu disimpulkan bahwa metode drill dapat meningkatkan kemampuan teknik dasar passing siswa. Akan tetapi, metode ini tidak digunakan pada proses pembelajaran. Metode game yang dibandingkan dengan metode drill digunakan untuk meningkatkan prestasi lompat jauh pada atlet. Penelitian tersebut dapat dilihat pada penelitian (Kurniawan, 2020) Mengingat usia anak sekolah dasar merupakan usia yang sedang gemarnya bermain, tentu metode ini sangat tepat digunakan untuk meningkatkan keterampilan bermain bola voli mini terutama pada kemampuan service atas. Hal itu senada dengan apa yang disampaikan (Astuti, 2017) bahwa metode bermain baik diterapkan pada siswa Sekolah dasar yang memiliki karakteristik senang bermain. Karakteristiik siswa yang gemar bermain ini dapat dikembangkan dalam penelitian selanjutnya dengan di kolaborasikan dengan games yang lebih beragam. Manfaat dari penelitian ini adalah karakteristik siswa yang gemar bermain dapat diaktualisasikan dan dikombinasikan dengan bola voli.

\section{SIMPULAN}

Berdasarkan hasil penelitian dan pembahasan dapat diambil kesimpulan bahwa penerapan metode pembelajaran game dapat meningkatkan kemampuan servis atas bolavoli mini para siswa. Pada siklus I, ketuntasan pembelajaran yang dicapai mencapai 55\% . Hasil tersebut masih belum mencapai harapan ketuntasan yakni $70 \%$ dari keseluruhan siswa dalam satu kelas penelitian. Pada siklus II ketuntasan pembelajaran sebanyak $85 \%$ siswa mampu melakukan teknik servis atas dengan baik. Dalam hal ini guru berperan tidak hanya menjadi pendamping namun juga sebagai pemberi wawasan yang luas terhadap siswa perihal materi pembelajaran servias atas bolavoli. Siswa yang tuntas yang nilainya melebihi Kriteria Ketuntasan Minimal (KKM) lebih dari 70\%, yaitu $75 \%$. Kesimpulan dari hasil pembelajaran dengan menggunakan metode pembelajaran game mulai dari siklus 1 sampai siklus 2 peningkatannya secara kumulatif termasuk tinggi. 
GURU MI, 4, 1-16.

\section{SIMPULAN}

Berdasarkan hasil penelitian dan pembahasan dapat diambil kesimpulan bahwa penerapan metode pembelajaran game dapat meningkatkan kemampuan servis atas bolavoli mini para siswa. Pada siklus I, ketuntasan pembelajaran yang dicapai mencapai 55\% . Hasil tersebut masih belum mencapai harapan ketuntasan yakni $70 \%$ dari keseluruhan siswa dalam satu kelas penelitian. Pada siklus II ketuntasan pembelajaran sebanyak $85 \%$ siswa mampu melakukan teknik servis atas dengan baik. Dalam hal ini guru berperan tidak hanya menjadi pendamping namun juga sebagai pemberi wawasan yang luas terhadap siswa perihal materi pembelajaran servias atas bolavoli. Siswa yang tuntas yang nilainya melebihi Kriteria Ketuntasan Minimal (KKM) lebih dari 70\%, yaitu $75 \%$. Kesimpulan dari hasil pembelajaran dengan menggunakan metode pembelajaran game mulai dari siklus 1 sampai siklus 2 peningkatannya secara kumulatif termasuk tinggi.

\section{DAFTAR PUSTAKA}

Arikunto, S. (2013). Manajemen Penelitian. Rineka Cipta.

Astuti, Y. (2017). Pengaruh Metode Drill dan Metode Bermain Terhadap Keterampilan Bermain Bola Voli Mini ( Studi Eksperimen Pada Siswa SD Negeri 14 Kampung Jambak Kecamatan Koto Tangah Kota Padang ). AL IBTIDA: JURNAL PENDIDIKAN
Atsani, M. R. (2020). Meningkatkan kemampuan passing bawah bolavoli menggunakan metode bermain. Edu Sportivo: Indonesian Journal of Physical Education, 1(2), 88-96.

Fanani, Z. (2020). Peningkatan kemampuan teknik dasar passing permainan bola voli melalui metode drill. Education Journal: Journal Education Research and Development, 4(1), 111-126. https://doi.org/https://doi.org/10.31537/ ej.v4i2.345

John, P. D. (2006). Lesson planning and the student teacher: re- thinking the dominant model. Journal of Curriculum Studies, 38(4), 483-498.

Kamil, A. I., Damrah, \& Indika, P. M. (2018). Pengaruh Metode Bermain Terhadap Kemampuan Passing. Sport Science: Jurnal Sain Olahraga Dan Pendidikan Jasmani, 18(2), 91-102. https://doi.org/http://doi.org/10.24036/j ss.v\%vi\%i.21

Kim, I. (2016). Exploring changes to a teacher's teaching practices and student learning through a volleyball content knowledge workshop. European Physical Education Review, 22(2), 225242.

Kurniawan, D. D. (2020). Pengaruh Latihan Metode Drill dan Game Terhadap Peningkatan Prestasi Lompat Jauh Pada Atlet Remaja. Sport Science and 
Journal of Sport Education (JOPE), 3 (1) 2020 - 62

Sukari $^{l}$, Tito Pangesti Adji ${ }^{2}$, Kukuh Hardopo Putro ${ }^{3}$.

Health, 2(3), 285-292.

Mahedero, P., Calderón, A., Arias-Estero, J. L., Hastie, P. A., \& Guarino, A. J. (2015). Effects of student skill level on knowledge, decision making, skill execution and game performance in a mini-volleyball Sport Education season. Journal of Teaching in Physical Education, 34(4), 626-641.

Palao, J. M., Manzanares, P., \& Ortega, E. (2009). Techniques used and efficacy of volleyball skills in relation to gender. International Journal of Performance Analysis in Sport, 9(2), 281-293.

Stolz, S., \& Pill, S. (2014). Teaching games and sport for understanding: Exploring and reconsidering its relevance in physical education. European Physical Education Review, 20(1), 36-71.

Supardi, S., \& Suharsimi, A. (2009). Penelitian Tindakan Kelas. Jakarta: Bumi Aksara. 